\title{
BIOVIGILÂNCIA: QUALIDADE E SEGURANÇA NO PROCESSO DE DOAÇÃO E TRANSPLANTE DE ÓRGÃOS E TECIDOS
}

DOI: 10.5327/Z1414-4425202000010001

A assistência à saúde nos diferentes cenários de cuidado é permeada de riscos, tanto ao paciente como ao profissional, não sendo diferente no processo de doação e transplante de órgãos e tecidos.

Segundo o Registro Brasileiro de Transplantes (RBT), no período entre janeiro e setembro de 2019, a lista de espera para o transplante contava com 36.468 pacientes. Nesse mesmo período, efetivaram-se 2.775 doações de órgãos e/ ou tecidos, e foram realizados mais de 20 mil transplantes (6.772 de órgãos sólidos, 10.995 de córnea e 2.575 de medula óssea) ${ }^{1}$.

Tais números vêm num crescente desde 2009, quando a Associação Brasileira de Transplante de Órgãos (ABTO) iniciou a consolidação e a publicação periódica desses dados ${ }^{1}$. A quantidade expressiva de transplantes revela que o Brasil é o país com o maior programa público desse tipo de procedimento do mundo 2 .

Nesse contexto, caracteriza-se o processo de doação-transplante como uma área de alta complexidade, e ele, portanto, envolve distintos profissionais e serviços em diferentes etapas, entre elas: identificação do potencial doador, diagnóstico de morte encefálica, entrevista familiar, manutenção do doador, cirurgia de retirada de múltiplos órgãos e tecidos, embalagem, armazenamento e transporte dos órgãos e/ ou tecidos para o centro transplantador, realização do transplante e acompanhamento do indivíduo transplantado.

Cada uma das etapas compreende riscos de eventos adversos que podem causar danos ao receptor, como a não realização do transplante, a transmissão de doenças e a ocorrência de infecções e/ou de complicações não esperadas no pós-transplante ${ }^{3}$. Na doação e no transplante intervivos, a preocupação e o cuidado com o doador, indivíduo hígido, aumentam ainda mais a complexidade do processo.

Diante disso, os profissionais de saúde têm grande responsabilidade no que concerne à qualidade e à segurança na assistência ao doador e ao receptor. O comportamento dos profissionais de saúde é fator decisivo na segurança do cuidado 4 . Sendo a comunicação o fator de impacto na segurança do paciente e dos profissionais em qualquer processo de saúde, a utilização de indicadores e a análise e a divulgação de resultados podem contribuir para melhores práticas no processo de doação e transplante.

Países como Itália, Espanha, Estados Unidos e Austrália têm desenvolvido e implantado sistemas de vigilância, visando mapear riscos e analisar eventos adversos e, com base nisso, propor medidas de segurança. Assim, a biovigilância corresponde a um conjunto de ações de monitoramento e controle que abrange todo o ciclo da doação e do transplante de órgãos e tecidos 5 .

No Brasil, o sistema de biovigilância tem sido implementado pelo Ministério da Saúde, via Agência Nacional de Vigilância Sanitária (ANVISA), por meio do componente do Sistema de Notificação e Investigação em Vigilância Sanitária (VIGIPOS). Ele é aplicado ao processo de doação e transplante de células, tecidos e órgãos ${ }^{5}$, propiciando aos envolvidos em ambas as etapas realizar a notificação de riscos e de eventos adversos.

A importância da notificação salienta-se pela possibilidade de gerar conhecimento e aprendizagem com as situações ocorridas e criar estratégias para aumentar a segurança e a qualidade nos processos ${ }^{3}$.

Destaca-se que melhorias na qualidade e na segurança no processo de doação e transplante pressupõem a adoção de indicadores e a análise de resultados que possam nortear melhores práticas assistenciais baseadas em evidências. Para isso, modelos de vigilância já implantados em outros países devem ser investigados ${ }^{2}$.

Assim, considerando o insuficiente número de doadores para suprir a lista de espera e que o transplante, frequentemente, é a única possibilidade de sobrevivência para muitos indivíduos, são necessários esforços coletivos, visando a maior qualidade e segurança no processo de doação e transplante de órgãos e tecidos ${ }^{2}$. Portanto, sistemas de biovigilância podem contribuir de forma significativa para resultados exitosos.

\section{Patrícia Treviso}

Pós-Doutoranda do Programa de Pós-Graduação em Enfermagem da Escola Paulista de Enfermagem da Universidade Federal de São Paulo (EPE-UNIFESP), São Paulo, Brasil. Professora assistente da Escola de Saúde: Enfermagem da Universidade do Vale dos Sinos (UNISINOS), Porto Alegre, Brasil. Membro do Grupo de Estudos em Doação e Transplante de Órgãos e Tecidos - GEDOTT. 


\section{Maria Helena Costa Amorim}

Professora titular visitante do Departamento em Saúde da Mulher da EPE-UNIFESP, São Paulo, Brasil.

\section{Janine Schirmer}

Professora Titular do Departamento de Enfermagem em Saúde da Mulher, Diretora da Escola Paulista de Enfermagem, Editora-Chefe da Revista Acta Paulista de Enfermagem e Vice-Presidente do Conselho Gestor do Hospital Universitário da UNIFESP. Membro do Grupo de Estudos em Doação e Transplante de Órgãos e Tecidos - GEDOTT.

\section{Bartira de Aguiar Roza}

Professora associada do Departamento de Clínica e Cirúrgica e supervisora de Pós-Doutorado do Programa de Pós-Graduação da EPE-UNIFESP, São Paulo, Brasil. Lider do Grupo de Estudos em Doação e Transplante de Órgãos e Tecidos - GEDOTT.

\section{REFERÊNCIAS}

1. Associação Brasileira de Transplantes de Órgãos (ABTO). Registro Brasileiro de Transplantes. Dados numéricos da doação de órgãos e transplantes realizados por estado e instituição no período: janeiro/março 2019 [Internet]. São Paulo: ABTO; 2019 [acessado em 30 jan. 2020]. Disponível em: http://www. abto.org.br/abtov03/Upload/file/RBT/2019/RBT-2019-jan-setcompleto.pdf

2. Roza BA, Kusahara DM, Pessoa JLE, Treviso P, Oliveira PC, Leite $\mathrm{RF}$, et al. Modelos e iniciativas de biovigilância e transplante: uma revisão narrativa. Vigil Sanit Debate. 2019;7(4):10-6. https://doi. org/10.22239/2317-269x.01403
3. StewartDE, TlustySM, TaylorKH, Brown RS, NeilHN, KlassenDK, etal. Trends and patterns in reporting of patient safety situations in transplantation. Am JTransplantation. 2015;15(12):3123-33. https://doi.org/10.1111/ajt.13528

4. McElroy LM, Daud A, Lapin B, Ross O, Woods DM, Skaro A, et al. Detection of medical errors in kidney transplantation: a pilot study comparing proactive clinician debriefings to a hospital-wide incident reporting system. Surgery. 2014;156(5):1106-15. https://doi.org/10.1016/j.surg.2014.05.013

5. Agência Nacional de Vigilância Sanitária (ANVISA). Guia de Biovigilância de Células, Tecidos e Órgãos \& Manual de Notificação. Brasília: Agência Nacional de Vigilância Sanitária; 2016. 